\title{
The stress and deflection analysis for the radial blades of the RCAC system
}

\author{
Yuan Mao Huang and Chii-Haur Chang \\ Department of Mechanical Engineering, National Taiwan University, \\ Taiwan, Republic of China \\ Received 16 May 1995; revised 1 June 1996
}

\begin{abstract}
The governing equations are derived by using the finite element method. The assumptions used in the analysis are that air properties in the blade segments are uniform and the rotor is a rigid body. A computer code is generated for the personal computer to reduce the cost of design. The calculated results of the stress and the deflection of the blades are compared and show good agreement with those obtained by the available software ABAQUS. The distributions of the stress and the deflection of the radial blades for the roto-cooler air conditioning system are analyzed. The locations and the magnitudes of the maximum stresses and the maximum displacement of the blades are determined. The calculated factor of safety of the blades is 11. (C) 1997 Elsevier Science Ltd and IIR
\end{abstract}

(Keywords: air conditioning; air compressor; expander; rotary compressor; design; mechanies; calculation)

\section{Analyse de contrainte et de déviation dans les aubes radiales d'un système de conditionnement d'air à refroidisseur à rotor}

\begin{abstract}
On obtient les équations directrices en utilisant la méthode des éléments finis. Dans l'analyse, on suppose que les propriétés de l'air dans les segments des palettes sont uniformes et que le rotor est rigide. On met au point un code informatique pour ordinateur PC, afin de réduire le coût de la conception. On compare les résultats calculés de contrainte et de déviation des palettes, et on obtient une bonne corrélation avec les résultats obtenus avec le logiciel ABAQUS. On analyse les distributions de contrainte et de déviation des palettes radiales du système de conditionnement d'air à refroidisseur à rotor. On détermine les localisations et les grandeurs des contraintes maximales et le déplacement maximal des palettes. Le facteur calculé de sécurité des palettes est 11. (C) 1997 Elsevier Science Ltd and IIR

(Mots clés: conditionnement d'air; compresseur d'air; détendeur; compresseur rotatif; conception; mécanique; calculation)
\end{abstract}

The performance of the roto-cooler air conditioning (RCAC) system with 10 blades as shown in Figure 1 was studied by Edwards and McDonald ${ }^{1}$ and Huang ${ }^{2}$. It was assumed that the air in the blade segments of the compression side and expansion side was compressed and expanded polytropically, respectively. The unsteady air flow in the heat exchanger was analyzed by Huang ${ }^{3}$ and Huang and $\mathrm{Ho}^{4}$. However, the stress and the factor of safety of the blades were not investigated. The length of the blade $l$ is $0.0394 \mathrm{~m}$, and the thickness $T_{\mathrm{v}}$ and the depth $t$ of the radial blades are arbitrarily chosen to be $0.0046 \mathrm{~m}$ and $0.1524 \mathrm{~m}$, respectively. The shape of the blade with a semi-circular tip is shown in Figure 2.

The boundary conditions of all points around the blade are required to be input for each analysis. Just changing the location of the blade with other parameters unchanged needs one set of the boundary condition. If the angular increment of the blade location is $n^{\circ}$, there are $360 / n$ sets of boundary conditions required. Although the software ABAQUS ${ }^{5}$ is available for the stress and the deflection analysis, it is 


\begin{tabular}{|c|c|c|c|}
\hline \multicolumn{4}{|c|}{ Nomenclature } \\
\hline$A$ & Area of element $\left(\mathrm{m}^{2}\right)$ & $\vec{P}_{s}$ & Surface force vector $(\mathrm{N})$ \\
\hline$A_{3 / 2}^{t}$ & $\begin{array}{l}\text { Relative tangential acceleration of } \\
\text { blade to rotor }\left(\mathrm{m} \mathrm{s}^{-2}\right)\end{array}$ & $p_{\mathrm{sp}}$ & $\begin{array}{l}\text { Pressure due to spring force acting } \\
\text { on blade bottom }\left(\mathrm{N} \mathrm{m}^{-2}\right)\end{array}$ \\
\hline$D_{\mathrm{ij}}$ & Distance between nodes $\mathrm{i}$ and $\mathrm{j}(\mathrm{m})$ & $\vec{Q}$ & Global displacement vector (m) \\
\hline$D_{\mathrm{pk}}$ & Distance between nodes $\mathrm{p}$ and $\mathrm{k}(\mathrm{m})$ & $\widetilde{\vec{q}}$ & Local displacement vector $(\mathrm{m})$ \\
\hline$E^{\mathrm{pn}}$ & Young's modulus of elasticity & $T$ & Temperature $(\mathbf{K})$ \\
\hline$\vec{F}_{A 2}^{\mathrm{n}}$ & $\begin{array}{l}\left(\mathrm{Nm}^{-2}\right) \\
\text { Centrifugal force of the rotor per }\end{array}$ & $\begin{array}{l}T_{\mathrm{v}} \\
t \\
V\end{array}$ & $\begin{array}{l}\text { Blade thickness }(\mathrm{m}) \\
\text { Blade width }(\mathrm{m})\end{array}$ \\
\hline$\vec{F}_{A_{3 / 2}}^{\mathrm{t}}$ & $\begin{array}{l}\text { Inertia force due to } A_{3 / 2}^{t} \text { per volume } \\
\left(\mathrm{N} \mathrm{m}^{-3}\right)\end{array}$ & $\begin{array}{l}X, Y \\
X, y\end{array}$ & $\begin{array}{l}\text { Global coordinates } \\
\text { Local coordinates }\end{array}$ \\
\hline $\overrightarrow{F_{\mathrm{b}}}$ & $\begin{array}{l}\text { Body force of element per volume } \\
\left(\mathrm{N} \mathrm{m}^{-3}\right)\end{array}$ & \multirow{2}{*}{\multicolumn{2}{|c|}{ Greek letters }} \\
\hline$\vec{F}_{\mathrm{c}}$ & Coriolis force of the blade per & $\begin{array}{l}\text { Greek } \\
\delta\end{array}$ & \\
\hline$\vec{F}_{\mathrm{d}}$ & $\begin{array}{l}\text { volume }\left(\mathrm{Nm}^{-3}\right) \\
\text { Force at the inner contact point of }\end{array}$ & $\tau$ & Shear stress $\left(\mathrm{MN} \mathrm{m}^{-2}\right)$ \\
\hline & rotor and blade $(\mathrm{N})$ & $\mu_{\mathrm{t}}$ & $\begin{array}{l}\text { Friction coefficient between stator } \\
\text { and blade }\end{array}$ \\
\hline$\vec{F}_{\mathrm{t}}$ & $\begin{array}{l}\text { Compressive force on the blade tip } \\
(\mathrm{N})\end{array}$ & $\mu_{\sigma}$ & Friction coefficient between rotor \\
\hline$\vec{F}_{\mathrm{u}}$ & $\begin{array}{l}\text { Force at the outer contact point of } \\
\text { rotor and blade }(\mathrm{N})\end{array}$ & $v$ & Poisson's ratio \\
\hline$\langle K\rangle$ & Stiffness matrix $\left(\mathrm{N} \mathrm{m}^{-1}\right)$ & $\begin{array}{l}\sigma \\
\theta_{\mathrm{h}}\end{array}$ & Stress $\left(\mathrm{N} \mathrm{m}^{-2}\right)$ \\
\hline$\langle k\rangle$ & Local stiffness matrix $\left(\mathrm{Nm}^{-1}\right)$ & & $\begin{array}{l}\text { Angular location or blade center } \\
\text { line (degree) }\end{array}$ \\
\hline$\langle N\rangle$ & $\begin{array}{l}\text { Blade length }(\mathrm{m}) \\
\text { Shape function matrix }\end{array}$ & $\theta_{\mathrm{v}}$ & Angle between $\vec{F}_{\mathrm{t}}$ and center line of \\
\hline$N_{\mathrm{t}}$ & Total number of elements & & \\
\hline$n_{\mathrm{cl}}$ & $\begin{array}{l}\text { Polytropical process exponential } \\
\text { constant }\end{array}$ & $\langle\lambda\rangle$ & Coordinate transform matrix \\
\hline$p_{\vec{a}}$ & Atmospheric pressure $\left(\mathrm{N} \mathrm{m}^{-2}\right)$ & \multicolumn{2}{|c|}{ Subscripts } \\
\hline$\vec{P}_{\mathrm{p}}$ & Body force vector $(\mathrm{N})$ & $x, y$ & Direction \\
\hline$\vec{P}_{\mathrm{i}}^{\mathrm{c}}$ & $\begin{array}{l}\text { Concentrated load }(\mathrm{N}) \\
\text { Inertia force vector }(\mathrm{N})\end{array}$ & $1,2,3$ & Blade segment or node point \\
\hline$P_{1}$ & $\begin{array}{l}\text { Force due to air pressure acting on } \\
\text { blade leading side }(\mathrm{N})\end{array}$ & \multicolumn{2}{|c|}{ Superscripts } \\
\hline$P_{\mathrm{r}}$ & $\begin{array}{l}\text { Force due to air pressure acting on } \\
\text { blade trailing side }(N)\end{array}$ & $\begin{array}{l}e \\
T\end{array}$ & $\begin{array}{l}\text { For element } \\
\text { Transpose of matrix }\end{array}$ \\
\hline
\end{tabular}

used in the main frame computer. In addition, it is inconvenient to generate the boundary conditions as required.

The purposes of this study are to calculate the distributions of the stresses and the deflections of the radial blade and to determine the maximum stresses, the maximum displacement and the factor of safety of the radial blades for the roto-cooler air conditioning system by generating a computer code which is used in the personal computer. This computer code can be specially used to generate automatically the elements and the required boundary conditions of the blades to reduce the cost of the design of the radial blades for the roto-cooler air conditioning system.

\section{Method of attack}

For counterclockwise rotation of the rotor, the air at essentially atmospheric pressure, $p_{\mathrm{a}}$, and temperature, $T_{\mathrm{a}}$, is drawn from the inlet duct into the blade segment $V_{\mathrm{i}}$ as shown in Figure 1. As the trailing blade arrives at the point $A$, the intake process is completed and the compression process begins. The air properties inside the blade segment are assumed to be uniform and the air is compressed polytropically with the polytropic exponent, $n_{\mathrm{cl}}$, until the leading blade of the blade segment $V_{2}$ arrives at the point $\mathrm{B}$. The air properties can be obtained from

$$
\left\{\begin{array}{l}
P_{2}=P_{1}\left(\frac{V_{1}}{V_{2}}\right)^{n_{c 1}} \\
T_{2}=T_{1}\left(\frac{V_{1}}{V_{2}}\right)^{n_{c 1}-1}
\end{array}\right.
$$

where the subscripts 1 and 2 represent the properties in the blade segment $V_{1}$ and $V_{2}$. 


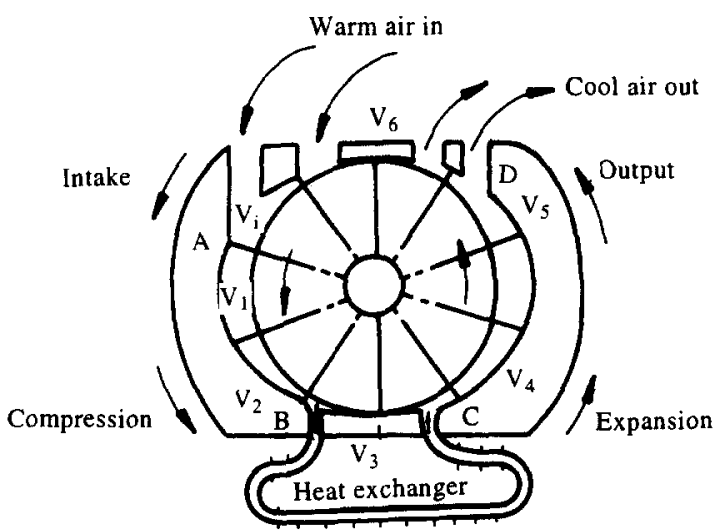

Figure 1 The RCAC system

Figure 1 Système de conditionnement d'air à refroidisseur à rotor

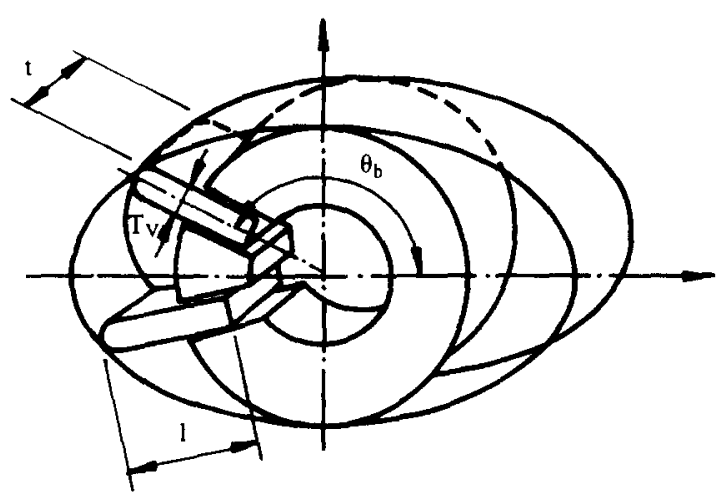

Figure 2 The shape of the blade

Figure 2 Forme des palettes

Most of the air is then pumped from the blade segment into the heat exchanger where the air is cooled down by rejecting heat out to the surrounding air. The unsteady air is assumed to be one-dimensional and flows through the heat exchanger with the circular cross-section. Similarly, the air is assumed to flow polytropically into the expansion blade segment from the outlet of the heat exchanger. The air is then pumped through the outlet duct into the space being cooled.

When the rotor rotates, the blades slide inward along the slot of the rotor during the compression process and outward during the expansion process. The thickness of the blade is relatively small compared with the depth and the length of the blade. Therefore, two-dimensional plane strain analysis is used in this study ${ }^{6}$. The dimension of the grid along the depth of the blade is much larger than that along the thickness of the blade.

The symbols using small letters and capital letters refer to the $x-y$ local coordinates and the $X-Y$ global coordinates, respectively. The symbols with the superscript (e) represent the element matrix, while symbols without the superscript represent the assembled matrix. The finite element method with the triangular element is used in this study ${ }^{710}$. The nodal displacements of the element are assumed to have a linear distribution.

The local vector of the nodal displacement is the assembled displacement vectors of all nodes relative to the $x-y$ local coordinates. The nodal displacements of an element can be expressed by the shape function which is the function of the coordinates of nodes and the area. The local strain vector and local stress vector can also be expressed as the function of the local vector of the nodal displacement.

Using the local displacement, local strain vector, local stress and strain relation of the element and transforming to the global coordinate, the potential energy of an element can be obtained. Applying the minimum potential energy theory yields

$$
\begin{aligned}
\langle K\rangle \vec{Q} & =\left(\sum_{e=1}^{N_{t}}\left\langle K^{(e)}\right\rangle \vec{Q}\right) \\
& =\vec{P}_{\mathrm{c}}+\sum_{e=1}^{N_{t}}\left(\vec{P}_{i}^{(e)}+\vec{P}_{b}^{(e)}+\vec{P}_{s}^{(e)}\right) \\
& =\vec{P}_{\mathrm{c}}+\vec{P}_{\mathrm{i}}+\vec{P}_{\mathrm{b}}+\vec{P}_{\mathrm{s}}
\end{aligned}
$$

where $\langle K\rangle$ is the global stiffness matrix and $N_{t}$ is the total number of elements. The relationship between the global stiffness matrix and the local stiffness matrix is

$$
\left\langle K^{(e)}\right\rangle=\left\langle\lambda^{(e)}\right\rangle^{T}\left\langle k^{(e)}\right\rangle\left\langle\lambda^{(e)}\right\rangle
$$

where

$$
\begin{aligned}
& \left\langle k^{(e)}\right\rangle=\frac{E \mathrm{t}}{4 A(1+v)(1-2 v)}\left[\begin{array}{ccc}
y_{32} & 0 & -x_{32} \\
0 & -x_{32} & y_{32} \\
-y_{31} & 0 & x_{31} \\
0 & x_{31} & -y_{31} \\
y_{21} & 0 & -x_{21} \\
0 & -x_{21} & y_{21}
\end{array}\right] \\
& {\left[\begin{array}{cccccc}
(1-v) y_{32} & -v x_{32} & (v-1) y_{31} & v x_{31} & (1-v) y_{21} & -v x_{21} \\
v y_{32} & (v-1) x_{32} & -v y_{31} & (1-v) x_{31} & v y_{21} & (v-1) x_{21} \\
\frac{2 v-1}{2} x_{32} & \frac{1-2 v}{2} y_{32} & \frac{1}{2}-2 v x_{31} & \frac{2 v-1}{2} y_{32} & \frac{2 v-1}{2} x_{21} & \frac{1-2 v}{1} y_{21}
\end{array}\right]}
\end{aligned}
$$

and

$$
\left\{\begin{array}{l}
x_{i j}=x_{\mathrm{i}}-x_{j} \\
y_{\mathrm{ij}}=y_{\mathrm{i}}-y_{j}
\end{array}\right\} \quad i=1,2,3 ; \quad j=1,2,3
$$

As shown in Figure 3, $\lambda_{1}, E_{2}$ and $D$ are the three locations with the concentrated load $\vec{P}_{\mathrm{c}}$. The contact point of the blade and the stator is at the point $D$. The spring force acting on the blade bottom is reduced to reduce the friction power loss. The semi-circular blade tip is simplified into a straight edge $B_{1} D B_{2}$ for generating the auto-mesh and reducing the computer time. The compressive force acting on the blade tip is 


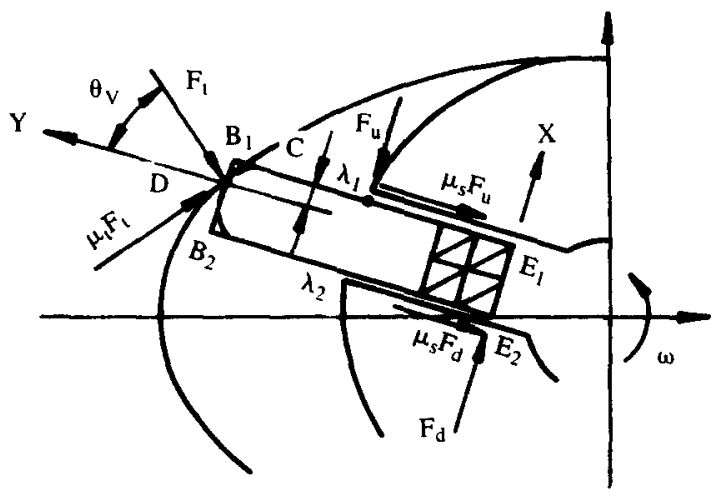

Figure 3 The concentrated loads acting on the blade

Figure 3 Charges concentrées agissant sur la palette

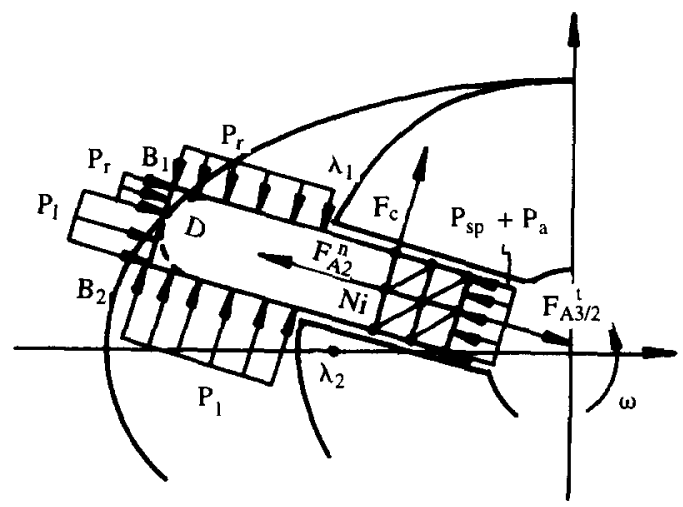

Figure 4 The body force and the surface force acting on the blade

Figure 4 Force d'inertie et forces agissant sur la surface de la palette

$\vec{F}_{\mathrm{t}}$, and the friction force at the blade tip is $\mu_{t} \vec{F}_{\mathrm{t}}$. The angle between $\vec{F}_{\mathrm{t}}$ and the center line of the slot is $\theta_{v}$. The normal force acting on the leading site at the bottom of the blade is $\vec{F}_{\mathrm{d}}$ and the friction force is $\mu_{\mathrm{s}} \vec{F}_{\mathrm{d}}$. The normal force acting on the trailing side of the blade at the front edge of the slot is $\vec{F}_{\mathrm{u}}$, and the friction force is $\mu_{\mathrm{s}} \vec{F}_{\mathrm{u}}$. So the concentrated load $\vec{P}_{\mathrm{c}}^{(e)}$ can be written as

$\vec{P}_{\mathrm{c}}^{(e)}=\vec{F}_{\mathrm{t}}^{(e)}+\mu_{\mathrm{t}} \vec{F}_{\mathrm{t}}^{(e)}+\vec{F}_{\mathrm{d}}^{(e)}+\mu_{\mathrm{s}} \vec{F}_{\mathrm{d}}^{(e)}+\vec{F}_{\mathrm{u}}^{(e)}+\mu_{\mathrm{s}} \vec{F}_{\mathrm{u}}^{(e)}$

Because the blade does not have an initial force, $\vec{P}_{i}^{(e)}$ is equal to zero. So the body force per volume is

$\vec{F}_{\mathrm{b}}^{(e)}=\vec{F}_{\mathrm{c}}^{(e)}+\vec{F}_{A_{3 / 2}}^{t(e)}+\vec{F}_{A 2}^{n(e)}$

The Coriolis force $\vec{F}_{\mathrm{c}}$ at a point in the blade due to the Coriolis acceleration is perpendicular to the slot as shown in Figure 4. The inertia force $\vec{F}_{A_{3 / 2}}^{t}$ due to the relative tangential acceleration $A_{3 / 2}^{t}$ of the blade to the rotor is parallel to the slot in the $Y$-direction. The direction of the centrifugal force $\vec{F}_{A 2}^{n}$ of the rotor is from the center of the rotor to the node.

The force $\vec{P}_{\mathrm{b}}^{(e)}$ can be written as

$\vec{P}_{\mathrm{b}}^{(e)}=\iint_{A^{(e)}}\langle N\rangle^{T} \vec{F}_{\mathrm{b}}^{(e)}(t \mathrm{~d} A)$

The force acting on the $\overline{D B_{1}}$ and $\overline{B_{1} \lambda_{1}}$ due to the air pressure as shown in Figure 3 is $P_{\mathrm{r}}$. The force acting on the $\overline{D B_{2}}$ and $\overline{B_{2} \lambda_{2}}$ due to the air pressure is $P_{1}$. The blade bottom $\overline{E_{1} E_{2}}$ is subjected to the atmospheric air pressure $p_{\mathrm{a}}$ and the pressure due to the spring force acting on the blade bottom, $p_{\text {sp }}$. The compressive force matrix acting on the surface $\overline{D B_{1}}, \overline{B_{1} \lambda_{1}}, \overline{D B}_{2}$, $\overline{B_{2} \lambda_{2}}$ and $\overline{E_{1} E_{2}}$, respectively, are

$$
\begin{aligned}
& \vec{P}_{\mathrm{s} 1}^{(e)}=\int\langle N\rangle^{T}\left[\begin{array}{c}
0 \\
-P_{\mathrm{r}}
\end{array}\right] t \mathrm{~d} l \\
& \vec{P}_{\mathrm{s} 2}^{(e)}=\int\langle N\rangle^{T}\left[\begin{array}{c}
-P_{\mathrm{r}} \\
0
\end{array}\right] t \mathrm{~d} l \\
& \vec{P}_{\mathrm{s} 3}^{(e)}=\int\langle N\rangle^{T}\left[\begin{array}{c}
0 \\
-P_{1}
\end{array}\right] t \mathrm{~d} l \\
& \vec{P}_{\mathrm{s} 4}^{(e)}=\int\langle N\rangle^{T}\left[\begin{array}{c}
P_{1} \\
0
\end{array}\right] t \mathrm{~d} l \\
& \vec{P}_{\mathrm{s} 5}^{(e)}=\int\langle N\rangle^{T}\left[\begin{array}{c}
0 \\
p_{\mathrm{sp}}+p_{\mathrm{a}}
\end{array}\right] t \mathrm{~d} l
\end{aligned}
$$

where $\mathrm{d} l$ in Equations (9)-(13) is the infinitesimal length along the surface line $\overline{D B_{1}}, \overline{B_{1} \lambda_{1}}, \overline{D B_{2}}, \overline{B_{2} \lambda_{2}}$, and $\overline{E_{1} E_{2}}$. Therefore,

$\vec{P}_{\mathrm{s}}^{(e)}=\sum_{e=1}^{N_{f}}\left(\vec{P}_{\mathrm{s} 1}^{(e)}+\vec{P}_{\mathrm{s} 2}^{(e)}+\vec{P}_{\mathrm{s} 3}^{(e)}+P_{\mathrm{s} 4}^{(e)}+\vec{P}_{\mathrm{s} 5}^{(e)}\right)$

The thickness of the blades is relatively smaller than the radius and the size of the rotor. The stiffness of the blades is smaller than that of the rotor. It is assumed that the rotor around the slot is rigid and no clearance exists between the blade and the slot. Therefore, the displacements of $\overline{\lambda_{1} E_{1}}$ and $\overline{\lambda_{2} E_{2}}$ in the $X$-direction are zero. It is also assumed that the contact point of the blade and the stator $D$ is the reference point of the displacement in the $Y$-direction. Therefore, the displacement of the point $D$ in the $Y$-direction is zero.

From Equation (1), $\left\langle K^{(e)}\right\rangle, \vec{P}_{\mathrm{i}}, \vec{P}_{\mathrm{b}}, \vec{P}_{\mathrm{s}}, \vec{P}_{\mathrm{c}}$ and all the boundary conditions, the global displacement vector $\vec{Q}$ can be determined. The local nodal displacement vector $\vec{q}^{(e)}$ can be obtained from

$\vec{q}^{(e)}=\left\langle\lambda^{(e)}\right\rangle \vec{Q}^{(e)}$

Therefore, the local stress vector $\vec{\sigma}^{(e)}$ and the local strain vector $\vec{\epsilon}^{(e)}$ can be obtained. Transferring to the global stresses, $\sigma_{X X}, \sigma_{Y Y}$ and $\sigma_{X Y}$ in the $X-Y$ global 
coordinates can be determined from

$$
\left\{\begin{aligned}
\sigma_{X X}= & \sigma_{x x}\left(\frac{X_{k}-X_{p}}{D_{p k}}\right)^{2}+\sigma_{y y}\left(\frac{X_{j}-X_{i}}{D_{i j}}\right)^{2} \\
& +2 \sigma_{x y}\left(\frac{X_{k}-X_{p}}{D_{p k}}\right)\left(\frac{X_{j}-X_{i}}{D_{i j}}\right) \\
\sigma_{Y Y}= & \sigma_{x x}\left(\frac{Y_{k}-Y_{p}}{D_{p k}}\right)^{2}+\sigma_{y y}\left(\frac{Y_{j}-Y_{i}}{D_{i j}}\right)^{2} \\
& +2 \sigma_{x y}\left(\frac{Y_{k}-Y_{p}}{D_{p k}}\right)\left(\frac{Y_{j}-Y_{i}}{D_{i j}}\right) \\
\sigma_{X Y}= & \sigma_{x x}\left(\frac{X_{k}-X_{p}}{D_{p k}}\right)\left(\frac{Y_{k}-Y_{p}}{D_{p k}}\right) \\
& +\sigma_{y y}\left(\frac{X_{j}-X_{i}}{D_{i j}}\right)\left(\frac{Y_{j}-Y_{i}}{D_{i j}}\right) \\
& +\sigma_{x y}\left[\left(\frac{X_{k}-X_{p}}{D_{p k}}\right)\left(\frac{Y_{j}-Y_{i}}{D_{i j}}\right)\right. \\
& \left.+\left(\frac{X_{j}-X_{i}}{D_{i j}}\right)\left(\frac{Y_{k}-Y_{p}}{D_{p k}}\right)\right]
\end{aligned}\right.
$$

where the nodes $i, j$ and $k$ are the three nodes of an element and the point $p$ is the intersection point of the line $i j$ and the line $p k$ which is perpendicular to the line $i j^{11}$.

\section{Results}

The data used in the analysis are the lengths of the stator major axis and the stator minor axis of $0.1524 \mathrm{~m}$ and $0.1168 \mathrm{~m}$, respectively, the clearance between the rotor and the stator of $0.0000762 \pm 0.0000254 \mathrm{~m}$, the ambient air temperature and pressure of $300.37 \mathrm{~K}$ and $101.3 \mathrm{Kpa}$, respectively, and the relative humidity of $25 \%$. The materials of the stator, the rotor and blades are vespel. The properties of vespel are Young's modulus of $2.7579 \mathrm{Gpa}$, Poisson's ratio of 0.41 , the friction coefficient of 0.11 , the ultimate tensile strength of $65.5 \mathrm{MPa}$ and $37.9 \mathrm{MPa}$ at $296 \mathrm{~K}$ and $533 \mathrm{~K}$, respectively ${ }^{12}$. The ultimate compressive strength with a strain of 0.1 is $133.1 \mathrm{MPa}$. The chosen polytropical process exponents for the compression side and the expansion side are 1.3 and 1.26, respectively, based on the experimental data.

The division of the elements for the blades is very important to obtain an accurate result. The length of the blade is divided into 150 sections and the thickness of the blade is divided into eight sections for CPS4R and CPE4R used for the software ABAQUS. These

Table 1 The total numbers of the elements and nodes Tableau 1 Nombres totaux des éléments et des noeuds

\begin{tabular}{lllllll} 
& & \multicolumn{2}{l}{ ABAQUS } \\
\cline { 3 - 6 } Number & $\begin{array}{l}\text { Current } \\
\text { triangle }\end{array}$ & B21 & CPE3 & CPS4R & CPE4R \\
\hline Elements & 2400 & 150 & 2400 & 1200 & 1200 \\
Nodes & 1359 & 151 & 1359 & 1359 & 1359 \\
\hline
\end{tabular}

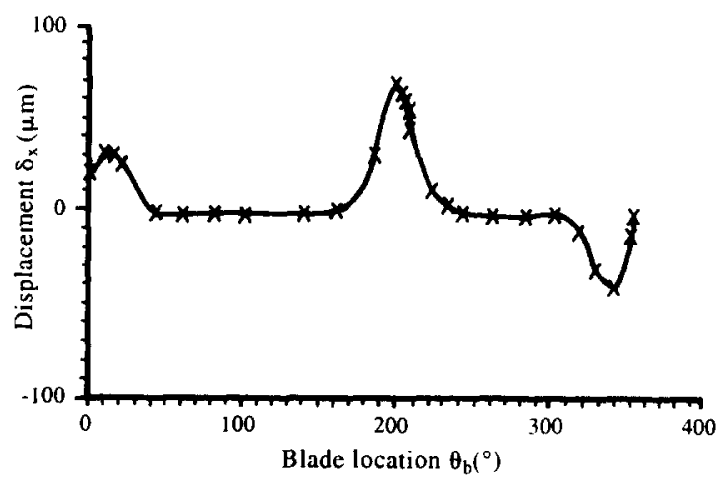

Figure 5 The maximum displacement in the $X$-direction versus the blade location

Figure 5 Déplacement maximal dans la direction $X$ par rapport à la localisation de la palette

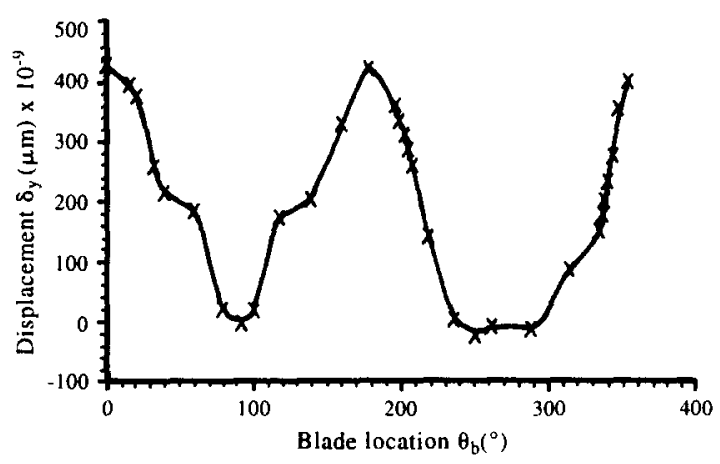

Figure 6 The maximum displacement in the $Y$-direction versus the blade location

Figure 6 Déplacement maximal dans la direction $Y$ par rapport à la localisation de la palette

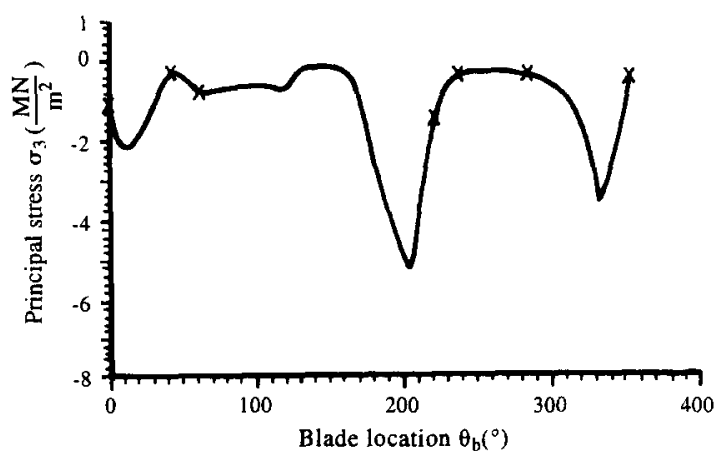

Figure 7 The compressive principal stress versus the blade location

Figure 7 Contrainte principale de compression par rapport $\dot{a}$ la localisation de la palette

rectangles are divided into two similar triangles for CPE3 and the current model. The total numbers of the elements and the nodes used for the current model and for the software ABAQUS are shown in Table 1.

The maximum displacements of the blade in the $X$-direction and the $Y$-direction shown in Figure 2 versus the location of the blade are shown in Figures 5 and 6 . The compressive principal stress and the 


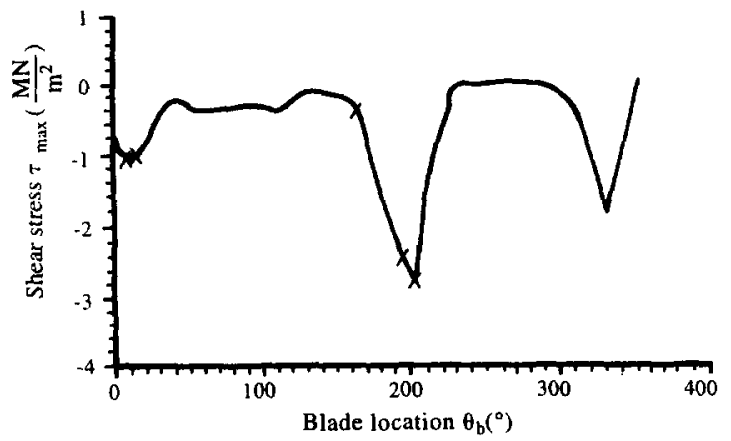

Figure 8 The maximum shear stress versus the blade location

Figure 8 Contrainte de déchirement maximale par rapport à la localisation de la palette

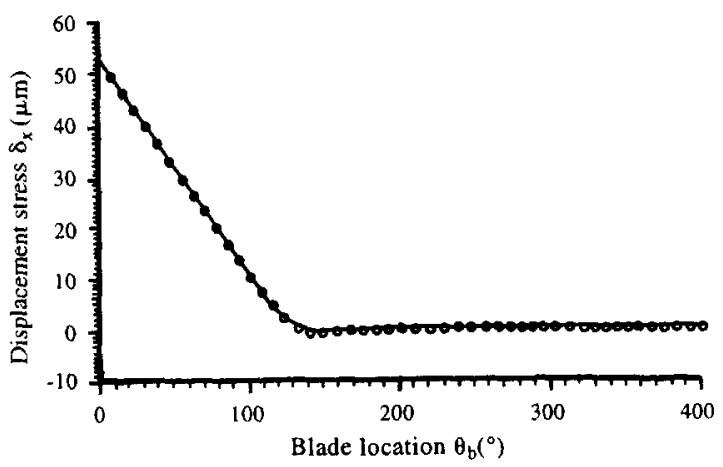

Figure 9 The displacement of the blade in the $X$-direction with $\theta_{\mathrm{b}}$ equal to $206^{\circ}$

Figure 9 Déplacement de la palette dans la direction $X$ avec $\theta b$ égal à $206^{\circ}$

$$
\sigma_{\mathrm{xx}}\left(\mathrm{M} \mathrm{N} / \mathrm{m}^{2}\right)
$$

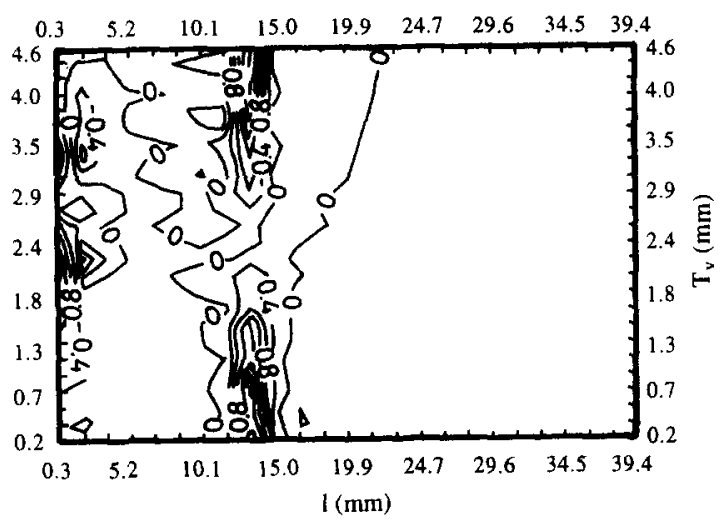

Figure 10 The contour plot of the normal stress $\sigma_{X X}$ with $\theta_{\mathrm{b}}$ equal to $206^{\circ}$

Figure 10 Graphique de la contrainte normale $\sigma_{X X}$ avec $\theta_{b}$ égal à $206^{\circ}$

maximum shear stress of the blade are shown in Figures 7 and 8 , respectively. The displacement in the $X$-direction along the blade from the blade tip toward the rotor center for $\theta_{\mathrm{b}}$ equal to $206^{\circ}$ is shown in Figure 9. The contour plots of the stresses $\sigma_{X X}, \sigma_{Y Y}$ and $\sigma_{X Y}$

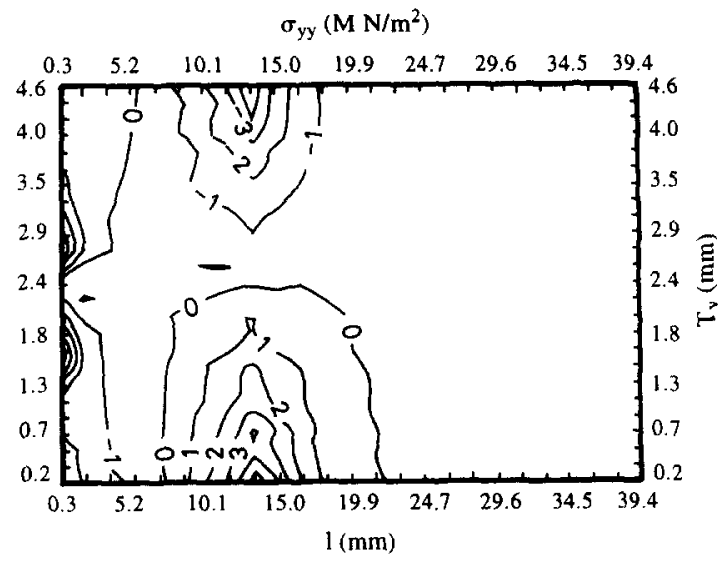

Figure 11 The contour plot of the normal stress $\sigma_{Y Y}$ with $\theta_{b}$ equal to $206^{\circ}$

Figure 11 Graphique de la contrainte normale $\sigma_{Y Y}$ avec $\theta_{b}$ égal à $206^{\circ}$

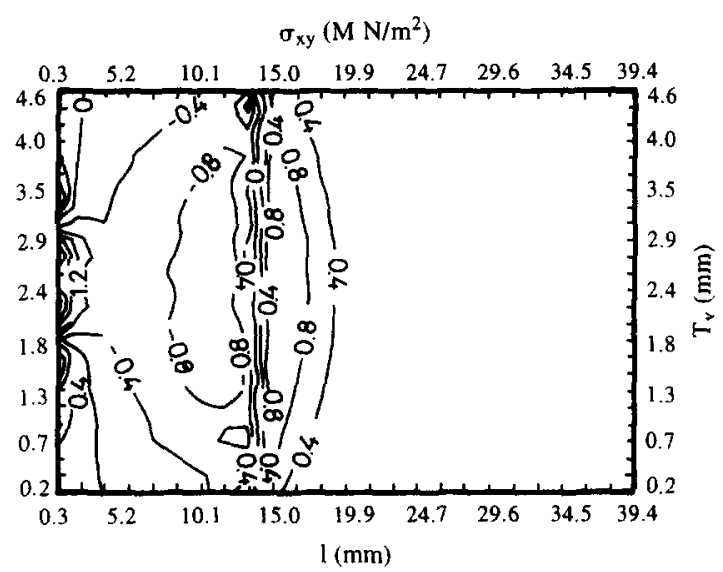

Figure 12 The contour plot of the shear stress $\sigma_{X Y}$ with $\theta_{\mathrm{b}}$ equal to $206^{\circ}$

Figure 12 Graphique de la contrainte de cisaillement $\sigma_{X Y}$ avec $\theta_{b}$ égal à $206^{\circ}$

of the blade are shown in Figures 10,11, and 12, respectively. The vertical coordinate, $T_{\mathrm{v}}$, is the blade thickness and the horizontal coordinate is the distance measured from the blade tip toward the rotor center.

The maximum displacement of the blade tip in the $X$-direction, the normal stresses in the $X$ direction and the $Y$-direction and the shear stress at the intersection point of the blade and the front edge of the slot, the maximum compressive principal stress and the maximum shear stress for the compression, and the normal stress in the $Y$-direction, the principal stress and the maximum shear stress for the tension with $\theta_{\mathrm{b}}$ equal to $206^{\circ}$ are shown in Table 2. The calculated results by using the software ABAQUS with four different element shapes B21, CPE3, CPS4R and CPE4R which are a one-dimensional linear element, a plane strain two-dimensional triangular element, a plain stress two-dimensional rectangular 
Table 2 The result of the displacement and the shear stresses for $\theta_{\mathrm{b}}$ equal to $206^{\circ}$

Tableau 2 Résultat du déplacement et contraintes de cisaillement pour $\theta_{b}$ égal à $206^{\circ}$

\begin{tabular}{|c|c|c|c|c|c|c|}
\hline & & \multirow{2}{*}{$\begin{array}{l}\text { Current } \\
\text { triangle }\end{array}$} & \multicolumn{4}{|c|}{ ABAQUS } \\
\hline & & & B21 & CPE3 & CPS4R & CPE4R \\
\hline \multirow[t]{6}{*}{ Compression } & $\delta_{X}(\mu \mathrm{m})$ & 63 & 42 & 52 & 52 & 42 \\
\hline & $\sigma_{X X}\left(\frac{M N}{m^{2}}\right)$ & -3.38 & & -1.78 & -3.40 & -3.40 \\
\hline & $\sigma_{Y Y}\left(\frac{M N}{m^{2}}\right)$ & -5.4 & -5.4 & -7.4 & -5.5 & -5.5 \\
\hline & $\sigma_{X Y}\left(\frac{M N}{m^{2}}\right)$ & 1.55 & & 0.95 & 0.6 & 0.6 \\
\hline & $\sigma_{3}\left(\frac{M N}{m^{2}}\right)$ & -6.3 & -5.7 & -7.4 & -5.8 & -5.8 \\
\hline & $\tau_{\max }\left(\frac{M N}{m^{2}}\right)$ & -3.1 & -2.7 & -3.6 & -3.0 & -1.3 \\
\hline \multirow[t]{3}{*}{ Tension } & $\sigma_{Y Y}\left(\frac{M N}{m^{2}}\right)$ & 4.8 & 5.2 & 6.5 & & 5.2 \\
\hline & $\sigma_{1}\left(\frac{M N}{m^{2}}\right)$ & 5.0 & 5.2 & 7.3 & & 5.2 \\
\hline & $\tau_{\max }\left(\frac{M N}{m^{2}}\right)$ & 2.4 & 2.5 & 3.7 & & 1.0 \\
\hline
\end{tabular}

element and a plane strain two-dimensional rectangular element, respectively, are also presented for comparison. The element used in the computer code generated for this analysis is same as the CPE3 element of the software ABAQUS ${ }^{5}$.

\section{Discussion}

The maximum displacements of the radial blade in the $Y$-direction are negligible compared with those in the $X$-direction as shown in Figures 5 and 6 . The maximum displacements of the blade in the $X$ - and $Y$ directions, the maximum compressive principal stress and the maximum shear stress occur when the angular location of the blade, $\theta_{\mathrm{b}}$, is equal to $206^{\circ}$ as shown in Figures 5, 6, 7 and 8 , respectively. The reason is that the difference in the air pressure acting on both sides of the blade has the largest value when the blade is at this location.

The maximum displacement of the blade in the $X$ direction occurs at the blade tip. It is shown in Figure 9 with $\theta_{\mathrm{b}}$ equal to $206^{\circ}$. The maximum normal stresses of the blade in the $X$-direction and the $Y$-direction with $\theta_{\mathrm{b}}$ equal to $206^{\circ}$ are located at $13.4 \mathrm{~mm}$ from the blade tip on both sides of the blade, which are the points of the blade at the front edge of the slot as shown in Figures 10 and 11 , respectively. The maximum shear stress of the blade with $\theta_{\mathrm{b}}$ equal to $206^{\circ}$ occurs at the blade tip as shown in Figure 12. There are stress concentrations occurring at locations of $13.4 \mathrm{~mm}$ from the blade tip on both sides of the blade and the blade tip with $\theta_{\mathrm{b}}$ equal to $206^{\circ}$. The high stresses occurring at these locations and at the blade tip are due to the stress concentration of contact. The stiffness matrix for the nodes of the elements with zero displacement is multiplied by $10^{6}$ in the analysis ${ }^{6}$. The calculated results are compared and show good agreement with the data obtained by using the software ABAQUS. The difference of the results mostly comes from the boundaries of the nodes with zero displacement. Since the rotor is assumed to be rigid and no clearance exists between the blade and the slot, the displacement of the blade at the blade tip and the maximum stresses should be larger than the calculated results. The blades are thin. It is assumed that the thermal stress due to the temperature gradient within the blades is negligible compared with the stresses due to the contact forces.

The air temperature is $384 \mathrm{~K}$ when the angular location of the blade, $\theta_{b}$, is equal to $206^{\circ}$. The maximum tensile strength of the blade is $55.3 \mathrm{MPa}$ by interpolation of the available data ${ }^{11}$. The calculated factor of safety for the blade is about 11. Therefore, the thinner blade can be used without causing failure of the blade and degrading the performance of the system.

\section{Acknowledgement}

The authors would like to express their sincere thanks to the National Science Council of the Republic of China for the grant NSC-82-0401-E002-425 to complete this study.

\section{References}

1 Edwards, T. C. and McDonald, A. T. ROVACS: A New Rotary Vane Air-Cycle Air Conditioning and Refrigeration System, SAE paper 720079 (1972)

2 Huang, Y. M. Analysis of the roto-cooler air-conditioning system Int. J. Refrig. (1995) 18(6)367372

3 Huang, Y. M. Study of unsteady flow in the heat exchanger by the method of characteristics, ASME J. Pressure Vessel Technol. (1992) (November) 114(4) 459-463

4 Huang, Y. M. and Ho, C. H. Study of the fluid flow in the elliptical duct by the method of characteristics ASME J. Pressure Vessel Technol (1993) (February) 115(1) 80-84

5 ABAQUS Theory Manual Ver. 4.8, Hillbbitt, Karlsson \& Sorensen, Inc,. (1989) 1.2.12, 3.2.3., 3.2.4., 3.3.3. and 4.2 .2 
6 Rao, S. S. The Finite Element Method in Engineering, Pergamon, Oxford (1989)

7 Burnett, D. S. Finite Element Analysis Addison Wesley (1987) 740-766

8 Reismann, H. and Pawlik, P. S. Elasticity Theory and Applications John Wiley \& Sons (1980) 185-187, 217-229

9 Zienkiewicz, O. C. and Morgan, K. Finite Elements and Approximation John Wiley \& Sons (1983) 105, 148-152
10

Cook, R. D., Malkus, D. S. and Plesha, M. E. Concepts and Applications of Finite Element Analysis John Wiley \& Sons (1989)

11 Ford, Sir Hugh Advanced Mechanics of Materials, John Wiley \& Sons (1977) 15-18

12 VESPEL, When It Absolutely Has To Work - Summary of Tipical Properties Vespel Polyimide Parts, Du Pont Company Fabricated Products Department VESPEL Parts Marketing Section 